\title{
SYNCHRONOUS AND ASYNCHRONOUS COMMUNICATION: A DETERMINING FACTOR IN THE GAP BETWEEN THE TEACHING ONLINE AND TRADITIONAL STATISTICS
}

\author{
Ángel Ojeda-Castro, Universidad del Turabo,ut_aojeda@suagm.edu \\ Juan Valera-Márquez, Universidad del Turabo,valeraj1@suagm.edu \\ Philip R. Murray-Finley, Universidad del Turabo, pmurray2@suagm.edu
}

\begin{abstract}
The purpose of this study was to compare the academic performance of online courses in statistics with traditional courses in statistic for MBA students at a private university in Puerto Rico. The research utilized an experimental study design for two groups, where a t test statistical analysis was used, with a $99 \%$ level of confidence. The population of the study was composed of 47 students, of which 20 were from the control group and 27 were from the experimental group. Students in the experimental group were exposed to the online courses through the platform Blackboard Collaborate, which incorporated asynchronous communication, synchronous communication, and virtual classrooms. Students in the control group were taught the equivalent statistic courses through the traditional face-to-face classroom method. The content for both groups were: Data Types, Measures of Central Tendency, Measures of Dispersion, Boxplot, Graphics, Scatter Plot, Sample Size, Confidence Estimates, Probability, Discrete and Continuous Distributions, Hypothesis Testing, z-Test, Variance Analysis, t-Test, ANOVA, Regression, and Correlation Analysis. The study found that the online courses that utilized the tools of asynchronous communication, synchronous communication, and the virtual classrooms were more effective than the traditional teaching method in graduate-level statistics courses. The study determined that high student participation while engaged in asynchronous and synchronous communication activities allowed a constant connection between the student and the professor, student with other students, and fostered higher student motivation. The results argue that teaching statistics and other courses in mathematics related fields no longer have to be dominated by face-to-face instruction, as the findings support that courses in the discipline of mathematics are successfully taught using innovative education techniques leveraging on synchronous communication technologies.
\end{abstract}

Keywords: Synchronous Communication, Asynchronous Communication, Statistics Course, Virtual Environments, Communication Strategies, Learning Management Systems, Distance Education, Online Learning, Graduate Education, Puerto Rico

\section{INTRODUCTION}

The turn of the Twenty-First Century has brought about the exponential grow of technology that has changed the way we teach and learn. Among these changes are, when, where, and how students take classes or receive educational instruction. The growth of educational technology now includes virtual learning environments, computer software and applications, Learning Management Systems (LMS), and other applications which all provide an ever-growing amount of digital and electronic pedagogical resources (Ojeda-Castro, Murray-Finley, and Sánchez-Villafañe, 2017). Barrett (2010) also argues that the emergence and integration of new technologies, coupled with a digital native student population, have created new virtual communities that facilitate pedagogical practices online. As a result, continuous learning has now become a necessity and demands that individuals are interconnected in a globalized world (Rincón, 2013). However, one's first experience in an online educational environment is a unique learning experience for both the professor and the student. As a result, this new experience must be supported by a whole new set of strategies that enhance distance education in order to be an effective teaching methodology. Consequently, the methods in which knowledge is delivered must be modified to suit the demands and new forms of communication (Kearns, 2016). Furthermore, the growing demand for online learning that has comes from both non-traditional students and traditional students alike, make the need for a platform for synchronous learning to be absolutely necessary. When educational institutions meet the high demand and interest in online learning that included conferencing and collaborating 
capabilities in real time, institutions are more able to expand its educational offerings and reach greater audiences (Blackboard Inc, 2016).

\section{LITERATURE REVIEW}

\section{Learning Management System}

There are several e-LMS or Learning Management Systems (LMS) that are available and delivered through the Internet. Some of the platforms widely used by universities in the world are Blackboard, Moodle, and Sakai. Most of these platforms offer excellent online teaching and learning experiences, are user-friendly, and represent exceptional resources for universities and schools to offer online programs, courses, or degrees. These systems allow virtual learning on campuses where students, professors, and administrators have the opportunity to share information, and complete any academic and administrative activities, as well as course delivery, content, communication, evaluations, and assessment. Obviously, the use of an LMS also makes access to lectures, learning exercises, educational materials, exams, audiovisuals, and academic resources readily available to the student and professor synchronously or asynchronously (Ojeda-Castro, Murray-Finley, Sánchez-Villafañe, Sharma and Rivera-Collazo, 2013). In addition, most LMSs have a system that allows educators to track student learning and outcomes, as well as provide opportunities for students to receive feedback from peers and the professor.

\section{Asynchronous and Synchronous Communications}

Asynchronous communication engages faculty and students by empowering constant interaction on related topics and collaboration on projects, assignments, learning activities, and research. Valencia, Huertas and Baracaldo (2014) argue that human interaction and communication are necessary conditions in order for learning to take place. As a result, it is paramount to produce and integrate effective and efficient asynchronous communications tools such as, forums, blogs, wikis, and emails. There is also an equal demand for synchronous communications tools such as, teleconferences, video conferences, and chats. By including asynchronous and synchronous tools in distance learning, it helps to generate suitable environments for the construction of knowledge, and the ability to interact with others to support learning and clarify doubts. The results of recent studies of asynchronous and synchronous communications relationships with course grades have had provide positive conclusive results, and many researchers considered it essential for supporting authentic learning in distance education (Watts, 2016). There is also a body of research that also supports that synchronous communication helps to reinforce the interpersonal interactions and socio-emotional relationships. On the other hand, synchronous communication reinforces personal involvement and increased motivation (Hrastingki, 2008). According to Watts (2016), synchronous interactions in learning environments helps students to feel more connected and engaged in the learning experiences, as well as promoting higher levels of satisfaction, and successful group and cooperative interactions. On the other hand, asynchronous communication lets students access historical information, including forums, solutions, documents, and images, and permits students and professors alike to build on the developments of previous class discussions or disseminated information that is archived in the course. Asynchronous learning and assignments also allow individual students to progress ahead without waiting for other slower students; therefore, enabling the efficient progress of faster students without wasting time or waiting for students who need more time. (Harada 2014).

\section{Teaching Statistics}

A great deal of literature supports that many benefits are ascertained through distance education, the use of virtual learning environments can potentially be a new way of teaching statistical concepts effectively. The use of statistics is one of the critical elements found in both scientific and social research. In some fields, such as business, social sciences, education, and STEM, statistical concepts are fundamental for different applications and research techniques and methodology. Because statistics are a vital element when conducting research, it is paramount to improving didactic and practical methods for teaching statistical methods (Carvalho, 2017). As result of the integration of computers into pedagogical approaches to teaching statistical methods, changes in curriculum, classroom activities, and students' options to learning have also occurred. Over the past two decades, technological tools have produced an impact on teaching and learning statistics, and have helped to support cognitive and sociocultural processes, as well as perform rapid statistical analyses. For example, the use of spreadsheets in teaching statistics helps students to organize and understand their data and information (Chaamwe and Shumba, 2016). Many benefits are also gained by synchronous communication in educational processes. One of the main advantages is the possibility of applying virtual collaborative learning methods. These methods improve teacher-student and student-student interaction by creating a dynamic learning environment, facilitating the teaching-learning process which promotes interaction in real time (Akarasriworn, 2013). A problem that has not been totally overcome in online education is the lack of a sense of 
community that can be found in virtual courses. This lack of a sense of community or belonging to the group can be overcome, to a large extent, with the use of synchronous communication tools in distance education. The use of these communication and engagement tools in statistics courses online has been deeply impacted by these type of tools ( Wu, et al. 2017).

\section{Communication Strategies}

Communication strategies in online educations entails the use of telecommunications tools in the process of teaching and learning that facilitate the connection between participants and the professor-facilitator by utilizing the pedagogical tools such as chats, emails, wikis, forums, video-conferencing and others (Betegon, Fossas, and Martínez, 2012).

\section{Problem}

A problem that has not been totally overcome in online education is the lack of a sense of community that can be found in virtual courses (Wu, et al. 2017). The growing demand for online learning that has comes from both nontraditional students and traditional alike, make the need for a platform for synchronous learning to be necessary (Kearns, 2016). Many researchers consider essential support authentic learning in distance education (Watts, 2016).

\section{Objective}

1. The aim of this study was to compare the academic performance of students who took online MBA statistics courses with students who took the same statistics courses in the traditional face-to-face classroom mode.

2. Teaching strategies through immersion for the student's academic performance.

\section{Hypothesis:}

The average academic performance of students taking the online statistics courses is the same as the students who take statistics courses in traditional modality courses in an MBA program. $\left(u_{\text {online }}=u_{\text {traditional }}\right)$.

\section{RESEARCH METHODOLOGY}

The study used a sample of 47 students who took statistics courses in an MBA Program at a private university, of which 20 were the control group, and 27 were the experimental group. Students in the experimental group were exposed to online courses which utilized the platform Blackboard Collaborate, asynchronous communication, synchronous communication, and virtual classrooms. The students in the control group were taught the equivalent statistic course through the traditional classroom method. The content for both groups were: Data Types, Measures of Central Tendency, Measures of Dispersion, Boxplot, Graphics, Scatter Plot, Sample Size, Confidence Estimates, Probability, Discrete and Continuous Distributions, Hypothesis Testing, z-Test, Variance Analysis, t-Test, ANOVA, Regression, and Correlation Analysis.

\section{Traditional Group}

The materials used for the control group were the hard copy of the textbook and exercises assigned by the professor that included five homework assignments, two exams, and a final exam. Each student took the course in the classroom in a traditional classroom setting. The students were taught to perform manual statistics, $\mathrm{R}$ and Excel software (MegaStat plugin) for two months.

\section{Online Group}

The students from the online group were provided orientation regarding completing their online assignments, accessing the e-book, and using the Blackboard Collaborate. Additionally, all sections (classes) in this group were required to follow a master lesson plan and content modules prepared by the instructional design team and professors. Strategies for evaluation and the evaluation of content such as eight pre-tests, eight discussion forums, eight free response quizzes, and a final exam were implemented. In addition to of available content 24 hours, 7 days a week, the students also had the opportunity to receive help synchronously and asynchronously through the virtual classroom with the professor twice a week for a period of two months. The students were taught to perform manual statistics, and how to use the Excel software (Mega-Stat plugin). 


\section{Issues in Information Systems \\ Volume 19, Issue 2, pp. 41-46, 2018}

\section{RESULTS}

The results of the study indicated that $29.63 \%$ of the students exposed to the online statistics courses obtained a final grade of $90 \%$ or greater, compared to $0 \%$ of those who took traditional courses. On the other hand, $44.44 \%$ of students exposed to online statistics courses obtained a final grade between $80 \%-89 \%$, while those who took it in traditional mode obtained $50 \%$. The $22.22 \%$ of the students exposed to online statistics courses obtained a final grade between $70 \%-79 \%$, compared with $35 \%$ of those who took it in traditional mode. Additionally, 3.70\% of the students exposed to the online statistics courses obtained a final grade between $60 \%-69 \%$, compared to $15 \%$ who took the traditional modality. Therefore, as Figure 1 illustrates, $96.29 \%$ of the students who took the online statistics courses obtained a final grade $\geq 70$ in the course, while only $75 \%$ of the students in traditional mode obtained a final grade greater than 70.

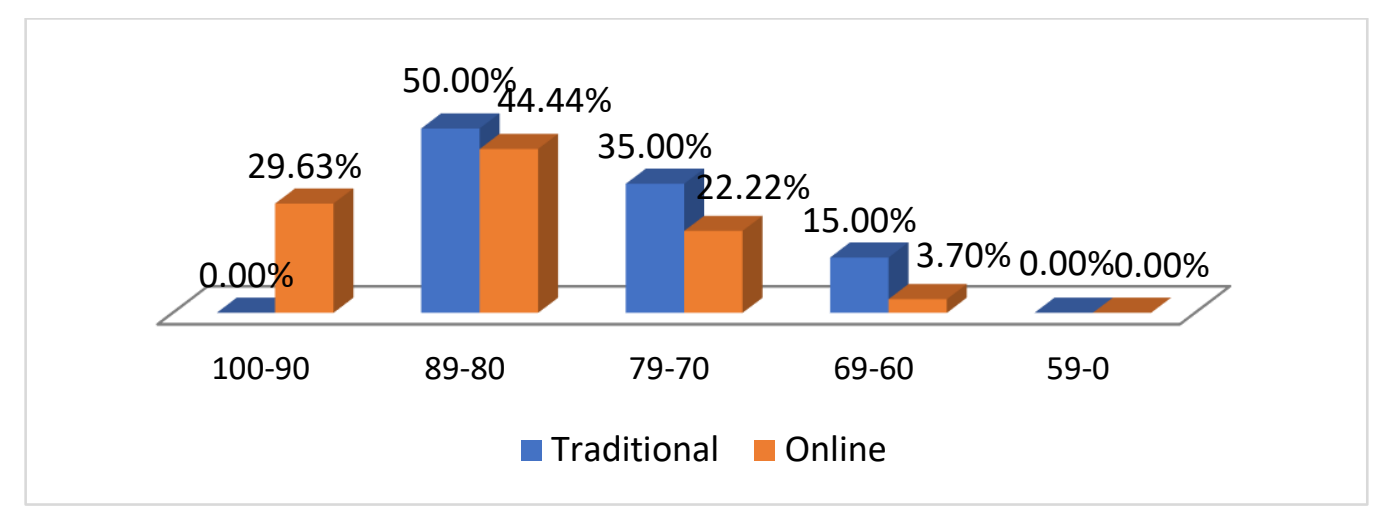

Figure 1. Distribution of Students' Final Grade

The results of the Kolmogorov-Smirnov normality test in Table 1 (p-value $=.200$ and $>0.05)$ and Table 2 (p-value $=$ .200 and > 0.05) indicate that the data collected from the final grade average are normally distributed in both the traditional group and the online group.

Table 1. Traditional normality test

\begin{tabular}{|c|c|c|c|c|c|c|}
\hline & \multicolumn{3}{|c|}{ Kolmogorov-Smirnov ${ }^{\mathrm{a}}$} & \multicolumn{3}{|c|}{ Shapiro-Wilk } \\
\hline & Statistic & df & Sig. & Statistic & df & Sig. \\
\hline Traditional & .150 & 20 & $.200^{*}$ & .944 & 20 & .284 \\
\hline
\end{tabular}

Table 2. Online normality test

\begin{tabular}{|l|r|r|r|r|r|r|}
\hline & \multicolumn{4}{|c|}{ Kolmogorov-Smirnov $^{\mathrm{a}}$} & \multicolumn{3}{c|}{ Shapiro-Wilk } \\
\cline { 2 - 7 } & Statistic & \multicolumn{1}{c|}{$\mathrm{df}$} & \multicolumn{1}{c|}{ Sig. } & Statistic & \multicolumn{1}{c|}{ df } & \multicolumn{1}{c|}{ Sig. } \\
\hline Experimental & .117 & 27 & $.200^{*}$ & .943 & 27 & .142 \\
\hline
\end{tabular}

The analysis of the variance of the average of final grades of the traditional group and online group in Table 3, indicate that the variances do not differ ( $p$-value $=0.437561$ and $>0.05$ ) between both groups. So, the variances of both groups behave the same. 
Issues in Information Systems

Volume 19, Issue 2, pp. 41-46, 2018

Table 3. F-Test Two-Sample for Variances

\begin{tabular}{lrr}
\hline & Online & \multicolumn{1}{c}{ Traditional } \\
\hline Mean & 84.07407 & 77.895 \\
Variance & 54.68661 & 50.60260526 \\
Observations & 27 & 20 \\
df & 26 & 19 \\
F & 1.080707 & \\
P $(\mathrm{F}<=$ f) one-tail & 0.437561 & \\
F Critical one-tail & 2.097821 & \\
\hline
\end{tabular}

The analysis of the t-Test in Table 4 indicates that the average of the final grades of the traditional group and the control group is not equal ( $\mathrm{p}$-value $=0.006102$ and $>0.01$ ), being the average of the group online, who obtained a better academic performance when it is compared with the traditional group.

Table 4. t-Test: Two-Sample Assuming Equal Variances

\begin{tabular}{lrr}
\hline & Variable 1 & Variable 2 \\
\hline Mean & 84.07407 & 77.895 \\
Variance & 54.68661 & 50.60260526 \\
Observations & 27 & 20 \\
Pooled Variance & 52.96225 & \\
Hypothesized Mean Difference & 0 & \\
$\mathrm{df}$ & 45 & \\
$\mathrm{t}$ Stat & 2.877982 & \\
$\mathrm{P}(\mathrm{T}<=\mathrm{t})$ one-tail & 0.003051 & \\
$\mathrm{t}$ Critical one-tail & 1.679427 & \\
$\mathrm{P}(\mathrm{T}<=\mathrm{t})$ two-tail & 0.006102 & \\
$\mathrm{t}$ Critical two-tail & 2.014103 & \\
\hline
\end{tabular}

\section{CONCLUSIONS}

Teaching online courses of statistic, that used the tools of asynchronous communication, synchronous communication, and the virtual classrooms is more effective than the traditional teaching method in graduate-level statistics courses. In online courses of statistic, synchronous communication is a critical factor for retention, student engagement, and student success in obtaining better academic performance. The possible lack of educational resources can be covered by the interventions of synchronous activities carried out by the professor. A high student participation in asynchronous and synchronous communication activities allows a constant connection between the student and the professor and creates high student motivation and engagement. Communication given by means of technological communication tools produce quality collaborative learning in distance education. The empirical evidence obtained accompanied by the reviewed literature, leads the researchers to propose that teaching statistics does not have to be exclusively taught in traditional face-to-face courses. It also supports that courses in mathematics and other STEM disciplines may be successfully taught using innovative education techniques leveraging on synchronous communication technologies. In the past, there were courses that were considered almost impractical to teach online due to the high complexity of its contents and the limitations that the communication resources suffered; however, those barriers have progressively disappeared making any courses of any specialty an adequate candidate to be administered in online education platforms duly equipped with the appropriate communication tools. 


\section{REFERENCES}

Akarasriworn Chatchada \& Ku Heng-Yu (2013). Graduate Students' Knowledge Construction and Attitudes Toward Online Synchronous Videoconferencing Collaborative Learning Environments. The Quarterly Review of Distance Education, 14(1), 35-48.

Barrett, B. (2010). Virtual Teaching and Strategies: Transitioning from Teaching Traditional Classes to Online Classes. Contemporary Issues in Education Research, 3(12), 17-20.

Betegon, L.; Fossas, M.; Martínez, E. \& Ramos, M. (2012). Entornos virtuales como apoyo a la docencia universitaria presencial: utilidad de Moodle. Anuario Jurídico y Económico Escurialense, XLIII, 273-302.

Blackboard Inc. (2016). The essential guide to synchronous learning, web conferencing and real-time collaboration moving beyond just-for-meeting tools to a solution purpose-built for the academic environment.

Retrieved from https://help.blackboard.com/Learn/Administrator/SaaS/User_Interface_Options/Learn_2016_Theme

Carvalho S. (2017). Combining Distance and Traditional Learning: A Study of the Use of Virtual Learning Environment Objects and Massive Online Open Courses in Statistics Class. International Journal of Information and Education Technology, 7(1).

Chaamwe N. \& Shumba L. (2016) ICT Integrated Learning: Using Spreadsheets as Tools for e-Learning, A Case of Statistics in Microsoft Excel. International Journal of Information and Education Technology, 6(6).

Harada Tomohiro \& Takamada Keiki. (2014). Asynchronously Evolving Solutions with Excessively Different Evaluation Time by Reference-based Evaluation. GECCO’14, July 12-16, 2014, Vancouver, BC, Canada. ACM 978-1-4503-2662-9/14/07.

Hrastinski, S. (2008). Asynchronous and synchronous e-learning: A study of asynchronous e-learning methods discovered that each supports different purposes. EDUCAUSE Quarterly, 32(4), 51-55.

Kearn, L. (2016). The experience of teaching online and its impact on faculty innovation across delivery methods. The Internet and Higher Education, 31, 71 - 78.

Ojeda-Castro, A., Murray-Finley, P., Sánchez-Villafañe, J., Sharma, M., \& Rivera-Collazo, A. (2013). The Effectiveness of Using the Educosoft Learning Management System to Teach Math in Puerto Rico. Issues in Information Systems, 14(2), 253-261.

Ojeda-Castro, A., Murray-Finley, P. \& Sánchez-Villafañe, J. (2017). Learning Management System Use to Increase Mathematics Knowledge and Skills in Puerto Rico. International Journal of Technology and Human Interaction, 13(2), 89-100.

Rincón, L. M. (2013). Evaluación piloto de las herramientas de comunicación sincrónicas y asincrónicas utilizadas en los cursos de metodología del trabajo académico y proyecto pedagógico una dista. Universidad Nacional Abierta y a Distancia. San Juan de Pasto, Colombia. Retrieved from https://repository.unad.edu.co/bitstream/10596/2494/1/30389861.pdf

Valencia, N. G., Huertas, A. P. \& Baracaldo, P. O. (2014). Los ambientes virtuales de aprendizaje: Una revisión de publicaciones entre 2003 y 2013, desde la perspectiva de la pedagogía basada en la evidencia. Revista Colombiana de Educación, 66.

Wu, W., Li, Ch. \& Yang, Q. (2017). Inferring students' sense of community from their communication behavior in online courses. UMAP '17, July 9-12, Bratislava, Slovakia. Retrieved from https://www.researchgate.net/publication/318293475_Inferring_Students'_Sense_of_Community_from_Th eir_Communication_Behavior_in_Online_Courses. 